\title{
Celastrus orbiculatus extract suppresses the epithelial-mesenchymal transition by mediating cytoskeleton rearrangement via inhibition of the Cofilin 1 signaling pathway in human gastric cancer
}

\author{
HAIBO WANG ${ }^{1-3}$, HAO GU $^{1-3}$, JUN FENG $^{1-3}$, YAYUN QIAN ${ }^{1-3}$, LIN YANG $^{1-3}$, FENG JIN $^{1-3}$, XUANYI WANG $^{1-3}$, \\ JUE $\mathrm{CHEN}^{1-3}$, YOUYANG SHI ${ }^{1-3}$, SONGHUA LU ${ }^{1-3}, \mathrm{MIN} \mathrm{ZHAO}^{1-3}$ and YANQING LIU ${ }^{1-3}$ \\ ${ }^{1}$ Yangzhou Cancer Research Institute; ${ }^{2}$ The Key Laboratory of Cancer Prevention and Treatment; ${ }^{3}$ Medical and \\ Pharmaceutical Institute, Yangzhou University, Yangzhou, Jiangsu 225009, P.R. China
}

Received November 3, 2015; Accepted April 21, 2017

DOI: $10.3892 / \mathrm{ol} .2017 .6470$

\begin{abstract}
Celastrus orbiculatus is a traditional medicinal plant used in the anti-inflammatory and analgesic treatment of various diseases. A previous study demonstrated that ethyl acetate extract of $C$. orbiculatus (COE) exhibited significant antitumor effects. However, studies concerning the effects and mechanism of COE in terms of suppressing the epithelial-mesenchymal transition (EMT) in human gastric adenocarcinoma cells have not been performed at present. The present study hypothesized that COE may inhibit EMT in gastric adenocarcinoma cells by regulating cell cytoskeleton rearrangement. The effect of COE on the viability of AGS cells was detected by MTT assay. An EMT model was induced by transforming growth factor- $\beta 1$. Cell cytoskeleton staining, laser scanning confocal microscopy and electronic microscopy were used to detect the changes in cell morphology and microstructure of gastric adenocarcinoma cells prior and subsequent to $\mathrm{COE}$ treatment. Invasion and migration assays were used to observe the effect of COE on the metastatic ability of AGS cells in vitro. The effect of COE on the expression of Cofilin 1 and EMT biomarkers, including Epithelial-cadherin, Neural-cadherin, Vimentin and matrix metalloproteinases, was examined by western blotting in AGS cells. The correlation between Cofilin 1 and EMT was investigated with immunofluorescence and cytoskeleton staining methods. The results demonstrated that $\mathrm{COE}$ may significantly inhibit the process of EMT in AGS cells, and that this was concentration-dependent. In addition, COE significantly downregulated
\end{abstract}

Correspondence to: Professor Yanqing Liu, Medical and Pharmaceutical Institute, Yangzhou University, 88 South University Avenue, Yangzhou, Jiangsu 225009, P.R. China

E-mail: liuyq@yzu.edu.cn

Key words: Celastrus orbiculatus, gastric cancer, Cofilin 1, epithelial-mesenchymal transition, cytoskeleton the level of Cofilin 1 in a concentration-dependent manner. In conclusion, these results suggested that Cofilin 1 was directly involved in the process of EMT in AGS cells, and that it served an important function. COE may significantly inhibit EMT in AGS cells, potentially by inhibiting the activation of the Cofilin 1 signaling pathway. The present study may provide a basis for the development of novel anticancer drugs and the development of novel therapeutic strategies, targeting Cofilin 1 protein.

\section{Introduction}

Gastric cancer has one of the highest incidence rates of all types of cancer globally, and the second highest mortality rate of all types of malignant tumor (1). As gastric cancer is frequently asymptomatic, the majority of tumor invasion and metastasis events occur prior to diagnosis of the patient at hospital. The high incidence of tumor metastasis and low sensitivity to chemotherapy in gastric cancer are important factors that restrict the improvement of gastric cancer survival rates (2). Epithelial-mesenchymal transition (EMT) is an important biological process through which malignant tumor cells derived from the epithelium obtain migration and invasion abilities. Following EMT, tumor cells lose epithelial cell polarity and their connection to the basement membrane, while their migration and invasion abilities, resistance to apoptosis and ability to degrade the extracellular matrix (ECM) are enhanced (3). Cofilin 1 is an important regulatory factor of EMT in tumor cells, demonstrating an association with the occurrence and development of tumors (4-6). Cofilin 1 may become a novel target for the treatment of malignant tumor growth and metastasis (7-10). Celastrus orbiculatus Thunb, a member of the Celastraceae family, is an important medicinal plant in China. Preliminary experimental studies have identified that the ethyl acetate extract of $C$. orbiculatus Thunb (COE) may significantly inhibit the proliferation, EMT, invasion and metastasis abilities of tumor cells $(11,12)$. However, the molecular mechanisms underlying the inhibition of EMT in tumor cells by COE remains unclear, and studies investigating 
the regulation of EMT by COE through Cofilin 1 pathways in tumors have not been performed at present. Identifying the mechanisms underlying COE-induced inhibition of tumor EMT processes and metastasis has significance for the identification and development of novel antitumor agents in traditional Chinese medicine (TCM). On the basis of previous studies by our group $(11,12)$, the present study examined EMT processes from the aspect of the cytoskeleton. The present study also revealed the mechanism underlying COE-induced inhibition of gastric cancer metastasis and invasion, which provides a basis for the development of novel antitumor TCM.

\section{Materials and methods}

Drugs. C. orbiculatus Thunb was purchased from Guangzhou Zhixin Pharmaceutical Co. Ltd. (Guangzhou, China) in July 2014 and stored at $4^{\circ} \mathrm{C}$. It was identified as Celastraceae by Professor Qin Minjian of China Pharmaceutical University (Nanjing, China). The extraction, purification and identification of the COE compounds was performed as described previously (13). COE was prepared at the Department of Chinese Materia Medica Analysis, China Pharmaceutical University (Nanjing, China). A detailed description of the preparation procedure has been described previously $(14,15)$. Briefly, dried stems of $C$. orbiculatus were pulverized and extracted using 95\% ethanol 3 times; the final extract was obtained by filtering, removing ethanol, and vacuum cold-drying the final extracts at $4^{\circ} \mathrm{C}$ for $6 \mathrm{~h}$. Finally, the extract was condensed, purified and lyophilized into powder at $4^{\circ} \mathrm{C}$, and stored at $4^{\circ} \mathrm{C}$ thereafter. The COE micro-powder was dissolved in dimethyl sulfoxide (DMSO) to $1 \%$ and was further diluted with RPMI-1640 medium (Gibco; Thermo Fisher Scientific, Inc., Waltham, MA, USA) to different concentrations (10, 20, 40, 80, 160 and $320 \mathrm{mg} / \mathrm{l}$ ) prior to use. The final concentration of DMSO in the medium did not exceed $0.1 \%$.

Reagents and antibodies. RPMI-1640 medium and fetal bovine serum (FBS) were acquired from Gibco; Thermo Fisher Scientific, Inc. MTT and tetramethylrhodamine (TRITC)-conjugated Phalloidin, an actin staining agent, were purchased from Sigma-Aldrich; Merck KGaA (Darmstadt, Germany). Recombinant transforming growth factor (TGF)- $\beta 1$ was obtained from R\&D Systems, Inc. (Minneapolis, MN, USA). Matrigel was purchased from BD Biosciences (San Jose, CA, USA). Antibodies against epithelial (E)-cadherin (cat no. 3195), neural (N)-cadherin (cat no. 4061), Cofilin 1 (cat no. 5175), vimentin (cat no. 5741), MMP-2 (cat no. 4022), MMP-9 (cat no. 13667) and $\beta$-actin (cat no. 3700) were purchased from Cell Signaling Technology, Inc. (Danvers, MA, USA). Other chemicals used of analytical grade were from commercial sources.

Cell culture.Human gastric cancer AGS cells were acquired from the Cell Bank of Type Culture Collection of Chinese Academy of Sciences, Shanghai Institute of Cell Biology (Shanghai, China). AGS cells were cultured in RPMI-1640 medium containing $10 \% \mathrm{FBS}$ and maintained at $37^{\circ} \mathrm{C}$ in a humidified incubator in an atmosphere of $5 \% \mathrm{CO}_{2}$. Cell morphology was visualized at x100 magnification with an optical microscope (IX72; Olympus Corporation, Tokyo, Japan).
EMT model. $10^{5}$ AGS cells were seeded in 6-well plates for $12 \mathrm{~h}$, then RPMI-1640 containing a concentration of $10 \mu \mathrm{g} / \mathrm{l}$ TGF- $\beta 1$ was added into each well, and cultured at $37^{\circ} \mathrm{C}$ for an additional $24 \mathrm{~h}$. To confirm the establishment of the model, the culture medium was removed, cells were washed twice with PBS and cell lysis buffer [20 mM Tris (pH 7.5), $150 \mathrm{mM}$ $\mathrm{NaCl}, 1 \%$ Triton X-100] was added. After $15 \mathrm{~min}$, all the liquid was collected into $1.5 \mathrm{ml} \mathrm{EP}$ tubes, and centrifuged at $8,000 \mathrm{x} \mathrm{g}$ at $4^{\circ} \mathrm{C}$ for $15 \mathrm{~min}$. The BCA kit (Beyotime Institute of Biotechnology, Haimen, China) was used to quantify the protein, and total protein $(50 \mu \mathrm{g})$ was separated using electrophoresis with a constant voltage of $110 \mathrm{~V}$ for $90 \mathrm{~min}$ in $10 \%$ SDS-PAGE gel. Following separation, proteins were transferred to a polyvinylidene (PVDF) membrane by electricity. The PVDF membrane was then washed 3 times, for $15 \mathrm{~min}$ each time, with $1 \mathrm{X}$ TBST (containing $0.1 \%$ Tween-20) wash buffer, then $5 \%$ skimmed milk powder solution was added for $2 \mathrm{~h}$ at room temperature. The membranes were subsequently washed again 3 times, for 15 min each time, with 1X TBST wash buffer. Primary antibodies were diluted to 1:1,000 with $5 \%$ skimmed milk powder solution and incubated with the membranes overnight at $4^{\circ} \mathrm{C}$, which were then washed 3 times, for 15 min each time, with $1 \mathrm{X}$ TBST wash buffer. Secondary antibodies were diluted to 1:1,000 in 5\% skimmed milk powder solution and incubated for $2 \mathrm{~h}$ at room temperature, then the membranes were washed 3 times, for 15 min each time, with 1X TBST wash buffer. A Bio-Rad protein gel imaging analysis system (Bio-Rad Laboratories, Inc., Hercules, CA, USA) was used to detect protein bands of the EMT biomarkers.

MTT measurement of cell viability and proliferation. AGS cells were plated at a density of 1,000 to 10,000 cells/well in a 96 -well plate, and incubated at $37^{\circ} \mathrm{C}$ for $12 \mathrm{~h}$. AGS cells were grouped into a negative control group (untreated), a model group $(10 \mu \mathrm{g} / 1 \mathrm{TGF}-\beta 1)$ and COE groups of different concentrations $(10,20,40,80$ and $160 \mathrm{mg} / \mathrm{l})$. The cells were cultured at $37^{\circ} \mathrm{C}$ for an additional 24,48 or $72 \mathrm{~h}$ following the treatments. At 24, 48 or $72 \mathrm{~h}$, cells were incubated with RPMI-1640 medium containing $0.5 \mathrm{mg} / \mathrm{ml} \mathrm{MTT}$ at $37^{\circ} \mathrm{C}$ for $4 \mathrm{~h}$. Formazan crystals were dissolved with $150 \mu \mathrm{l}$ DMSO. The absorbance of each well, including blanks, was measured at $490 \mathrm{~nm}$ in an automatic microplate reader subsequent to $10 \mathrm{~min}$ oscillation. The formula of the cell growth inhibition rate was as follows: Inhibition rate $=(1-$ absorbance of COE group/absorbance of blank control group) $\mathrm{x} 100 \%$.

Cell invasion and migration assays. Cell invasion and migration assays were performed using a Transwell membrane (Corning Incorporated, Corning, NY, USA) according to the manufacturer's protocol. For the invasion assay, Matrigel was applied to the upper chamber. AGS cells $\left(10^{4}\right)$ were seeded into the upper chamber and treated with RPMI-1640 medium containing different concentrations (10, 20, 40, 80 and $160 \mathrm{mg} / \mathrm{l})$ of COE. Media containing $10 \%$ FBS and TGF- $\beta 1$ were added to the lower chamber for $24 \mathrm{~h}$ as a chemoattractant. At the end of the treatment, the cells on the upper surface of the membrane were removed by cotton swabs and cells invading across the Matrigel to the lower surface of the membrane were fixed with $95 \%$ methanol and stained with $0.1 \%$ crystal violet. Images were captured under a microscope 

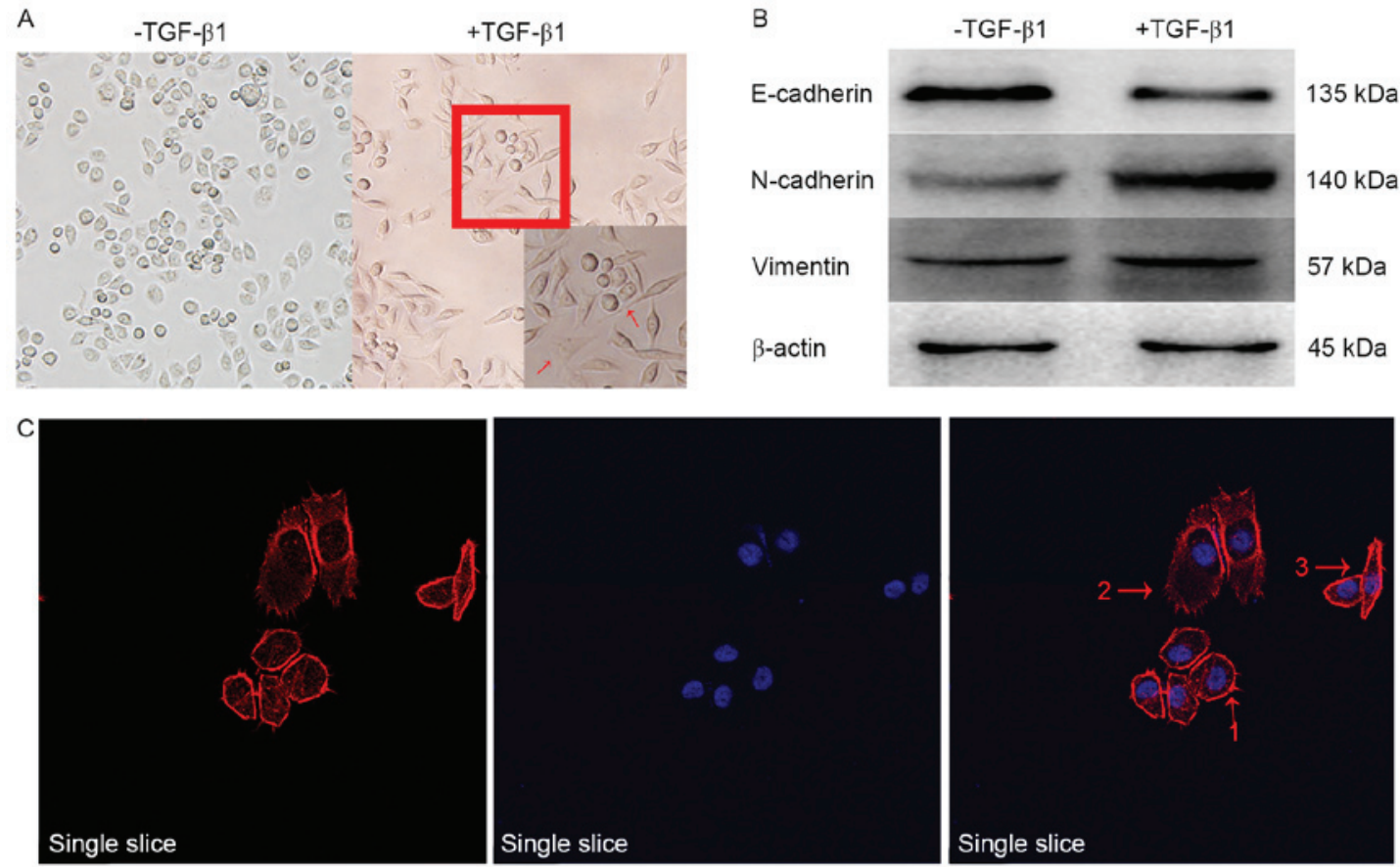

Figure 1. (A) Morphological changes prior and subsequent to TGF- $\beta 1$ treatment (magnification, $x 100)$. In the red box, cells were enlarged to show the formation of pseudopodia, indicated by the red arrows. (B) Changes to levels of epithelial-mesenchymal transition biomarkers prior and subsequent to TGF- $\beta 1$ treatment. (C) Arrow 1 indicates cell filopodia and arrow 2 indicates cell lamellipodia. Arrow 3 indicates gradual alterations in cell morphology from the irregular polygon form of epithelial cells into the spindle or fusiform form of interstitial cells (magnification, $\mathrm{x} 200$ ). TGF- $\beta 1$, transforming growth factor $\beta 1$; E-cadherin, epithelial cadherin; N-cadherin, neural cadherin.

at x200 magnification (Nikon Corporation, Tokyo, Japan) and invading cells were quantified by manual counting 5 fields of view. Migration assays were performed using the same procedure, except that the polycarbonate membrane was not coated with Matrigel. Each experiment was repeated 3 times.

Association between Cofilin 1 expression and EMT. AGS cells were passaged and cultured in RPMI-1640 medium until they reached $50-60 \%$ confluence. Cultured cells were fixed with 4\% paraformaldehyde in 1X PBS for 15-20 min at room temperature. Following 2 washes, cultured cells was permeabilized with $0.1 \%$ Triton X-100 for $1-5 \mathrm{~min}$ at room temperature. Following 2 washes, blocking solution [5\% bovine serum albumin (BSA) in 1X PBS] was applied to the cultured cells for $30 \mathrm{~min}$ at room temperature. Primary antibodies (Anti-Cofilin 1) were diluted to $1: 500$ with $5 \%$ BSA and incubated at $4{ }^{\circ} \mathrm{C}$ for 12-18 h. Following an additional 2 washes with $1 \mathrm{X}$ wash buffer, fluorescein isothiocyanate-labeled (1:500; AP124F) and TRITC-conjugated anti-Phalloidin secondary antibodies (1:100; SC-209) were diluted with 1 X PBS immediately prior to use and incubated for 30-60 min at room temperature.

Detection of Cofilin 1, matrix metalloproteinase (MMP)-2 and MMP-9. 10 AGS cells were seeded into 6-well plates. A negative control group, model group and groups of different concentrations $(20,40$ or $80 \mathrm{mg} / \mathrm{l})$ of COE were prepared and incubated at $37^{\circ} \mathrm{C}$ for $1 \mathrm{~h}$. Then $10 \mu \mathrm{g} / 1 \mathrm{TGF}-\beta 1$ was added into each well and incubated at $37^{\circ} \mathrm{C}$ for an additional $24 \mathrm{~h}$. Proteins were extracted from each group as previously described. A Bio-Rad protein gel imaging analysis system (Bio-Rad Laboratories, Inc.) was used to detect protein bands.
Cell microfilament cytoskeleton staining. AGS cells $\left(10^{5}\right)$ were seeded into 6-well plates. A negative control group, model group and groups of different concentrations (mass concentration of 20,40,80 mg/l) of COE were prepared. Cells were passaged and cultured in RPMI-1640 medium until they reached $50-60 \%$ confluence. Cultured cells were fixed with 4\% paraformaldehyde in 1X PBS for 15-20 min at room temperature. Suitable media was washed twice with $1 \mathrm{X}$ wash buffer, and permeabilized with $0.1 \%$ Triton X-100 in 1X PBS for 1-5 min at room temperature. Following 2 washes with $1 \mathrm{X}$ wash buffer, cells in suitable media were covered with dilute TRITC-conjugated Phalloidin in 1X PBS immediately prior to use, and incubated for 30-60 min at room temperature to stain the actin. Following this washing step, nuclei counterstaining was performed by incubating cells with $0.1 \mu \mathrm{g} / \mathrm{ml}$ DAPI for 1-5 min at room temperature, followed by 3 washes with $1 \mathrm{X}$ wash buffer, for 5-10 min each time. Fluorescence images were captured with a laser scanning confocal microscope (FV3000; Olympus Corporation).

Statistical analysis. Data processing was performed with SPSS software (version 16; SPSS Inc., Chicago, IL, USA), using one-way analysis of variance, followed by a Bonferroni post-hoc test. Data are expressed as the mean \pm standard deviation. $\mathrm{P}<0.05$ and $\mathrm{P}<0.01$ were considered to indicate a statistically significant difference.

\section{Results}

EMT model group. The cell morphology of the EMT model group was observed (Fig. 1). Marked changes occurred in 
Table I. Inhibition of AGS cell invasion and metastasis by COE.

\begin{tabular}{lccc}
\hline $\begin{array}{l}\text { Transforming } \\
\text { growth factor- } \beta 1 \\
(10 \mu \mathrm{g} / \mathrm{l})\end{array}$ & $\begin{array}{c}\mathrm{COE} \\
(\mathrm{mg} / \mathrm{l})\end{array}$ & $\begin{array}{c}\text { No. of } \\
\text { invading cells }\end{array}$ & $\begin{array}{c}\text { No. of } \\
\text { migrating cells }\end{array}$ \\
\hline- & 0 & $110.4 \pm 7.64$ & $221.8 \pm 29.56$ \\
+ & 0 & $137.8 \pm 6.38^{\mathrm{a}}$ & $384.2 \pm 22.75^{\mathrm{a}}$ \\
+ & 10 & $105.4 \pm 9.24^{\mathrm{a}, \mathrm{b}}$ & $288.4 \pm 20.65^{\mathrm{a}, \mathrm{b}}$ \\
+ & 20 & $77.8 \pm 7.92^{\mathrm{a}, \mathrm{b}}$ & $191.0 \pm 20.11^{\mathrm{a}, \mathrm{b}}$ \\
+ & 40 & $38.4 \pm 13.35^{\mathrm{a}, \mathrm{b}}$ & $85.2 \pm 18.77^{\mathrm{a}, \mathrm{b}}$ \\
\hline
\end{tabular}

${ }^{\mathrm{a}} \mathrm{P}<0.05$ vs. control; ${ }^{\mathrm{b}} \mathrm{P}<0.05$ vs. model. Data are presented as the mean \pm standard deviation. COE, Celastrus orbiculatus extract.

the morphology of cells, as visualized under a microscope. Cells with an originally irregular polygon morphology form gradually became spindle-shaped or fusiform, with high levels of pseudopodia identified around the cells, indicating that the cells had transitioned from epithelial cells into mesenchymal cells. The cells grew pseudopodia, and moved from their original congregated formations into dispersed populations, as demonstrated in Fig. 1A and C. Through EMT, the epithelial cells lost their epithelial phenotype, including cell polarity and the connection with the basement membrane. Following this transformation, cells achieved a mesenchymal phenotype, including an increased capacity for migration and invasion, an increased resistance to apoptosis and the ability to degrade the ECM. Additional examination of the levels of classical EMT-associated biomarker levels revealed that the expression of the epithelial biomarker E-cadherin, which mediates cell-to-cell homogenous adhesion, was markedly decreased while the expression levels of the interstitial markers N-cadherin and vimentin, which mediate cell-cell matrix heterogeneous adhesion, were markedly increased, as demonstrated in Fig. 1B. The results indicated that the classical biological markers of EMT, induced by TGF- $\beta 1$, were markedly altered in human AGS gastric cancer cells compared with untreated controls, which suggested that the transformation of epithelial cells to mesenchymal cells occurred. EMT is an important biological process during which malignant tumor cells derived from epithelial cells obtain migratory and invasive abilities. TGF- $\beta 1$ may successfully induce EMT in the AGS cell line.

Cell viability. The AGS cell control group grew well in vitro. Compared with the control group, AGS cells treated with 10-320 mg/l COE exhibited a concentration- and time-dependent inhibition of viability, as indicated by Fig. 2. Compared with the control group, cells treated with $40 \mathrm{mg} / \mathrm{l} \mathrm{COE}$ for 12 and $24 \mathrm{~h}$, and cells treated with $20 \mathrm{mg} / \mathrm{l} \mathrm{COE}$ for $48 \mathrm{~h}$ exhibited marked growth inhibition $(\mathrm{P}<0.05)$. In order to exclude the cytotoxic effect of COE on EMT in cells, low concentrations $(10,20,40 \mathrm{mg} / \mathrm{l})$ of COE were used to treat AGS cells for $24 \mathrm{~h}$ in subsequent experiments to investigate the inhibitory effect of COE on AGS cell viability. Concomitantly, the $50 \%$ inhibitory concentration of COE was $83.5 \mathrm{mg} / \mathrm{l}$ at $24 \mathrm{~h}$.

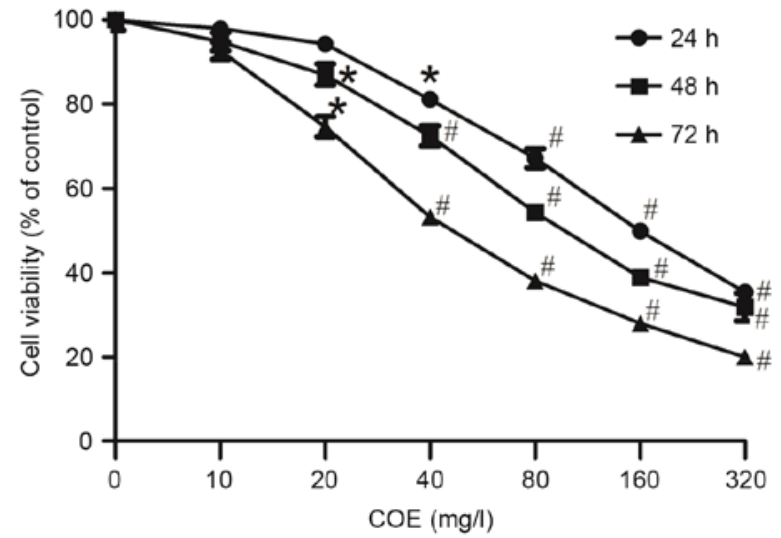

Figure 2. The inhibition of AGS cell viability induced by COE was concentration- and time-dependent. ${ }^{*} \mathrm{P}<0.05$ and ${ }^{\#} \mathrm{P}<0.01$ vs. control. COE, Celastrus orbiculatus extract.

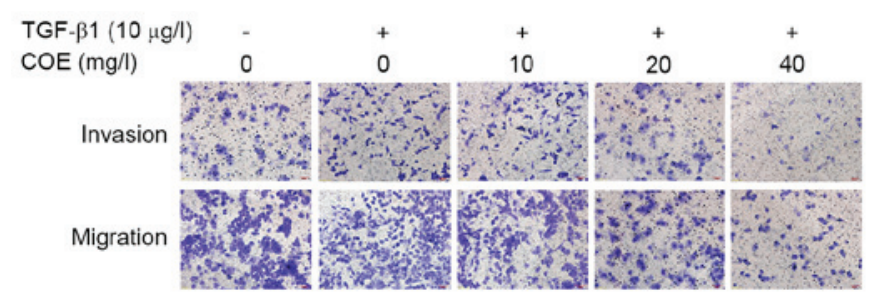

Figure 3. COE inhibits AGS cell invasion and metastasis (magnification, $\mathrm{x} 100)$. COE, Celastrus orbiculatus extract; TGF- $\beta 1$, transforming growth factor $\beta 1$.

Effect of COE on invasion and migration of AGS cells. A negative control group, model group and groups treated with 10 , 20 or $40 \mathrm{mg} / \mathrm{l} \mathrm{COE}$ were prepared. Compared with the model group, the number of cells invading through the membrane was significantly decreased following treatment with 10,20 or $40 \mathrm{mg} / \mathrm{l} \mathrm{COE}$ for $24 \mathrm{~h}(\mathrm{P}<0.05)$, as demonstrated as Fig. 3 and Table I. COE may significantly inhibit AGS cell invasion and metastasis.

Association between cofilin 1 expression and EMT. Through a combined immunofluorescence and cytoskeleton staining method, it was clear that an increased level of Cofilin 1 expression accompanied the stretching out of lamellipodia and filopodia in the cells undergoing EMT. The high expression of Cofilin 1 in the EMT cells was demonstrated with dark green staining, as compared with the normal control cells. A number of cells demonstrated Cofilin 1 expression in normal control cells (red box; Fig. 4). This suggested that Cofilin 1 was directly involved in the process of EMT in AGS cells, and served an important function.

Expressions of cofilin 1, E-cadherin, $N$-cadherin, vimentin, $M M P-9$ and MMP-2. AGS cells were treated with different concentrations of COE for $24 \mathrm{~h}$. The western blotting results suggested that Cofilin 1, N-cadherin, vimentin, MMP-2 and MMP-9 protein expression was markedly decreased with increasing concentrations of COE compared with the model group, while the expression level of E-cadherin protein increased, as demonstrated in Fig. 5. 


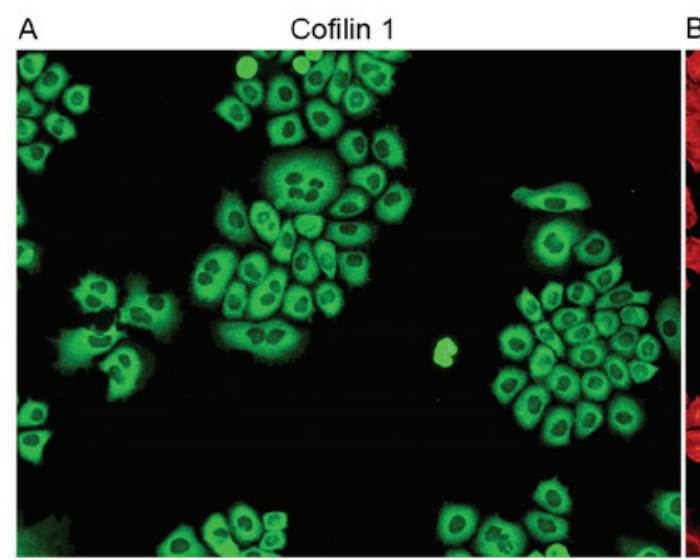

B Actin
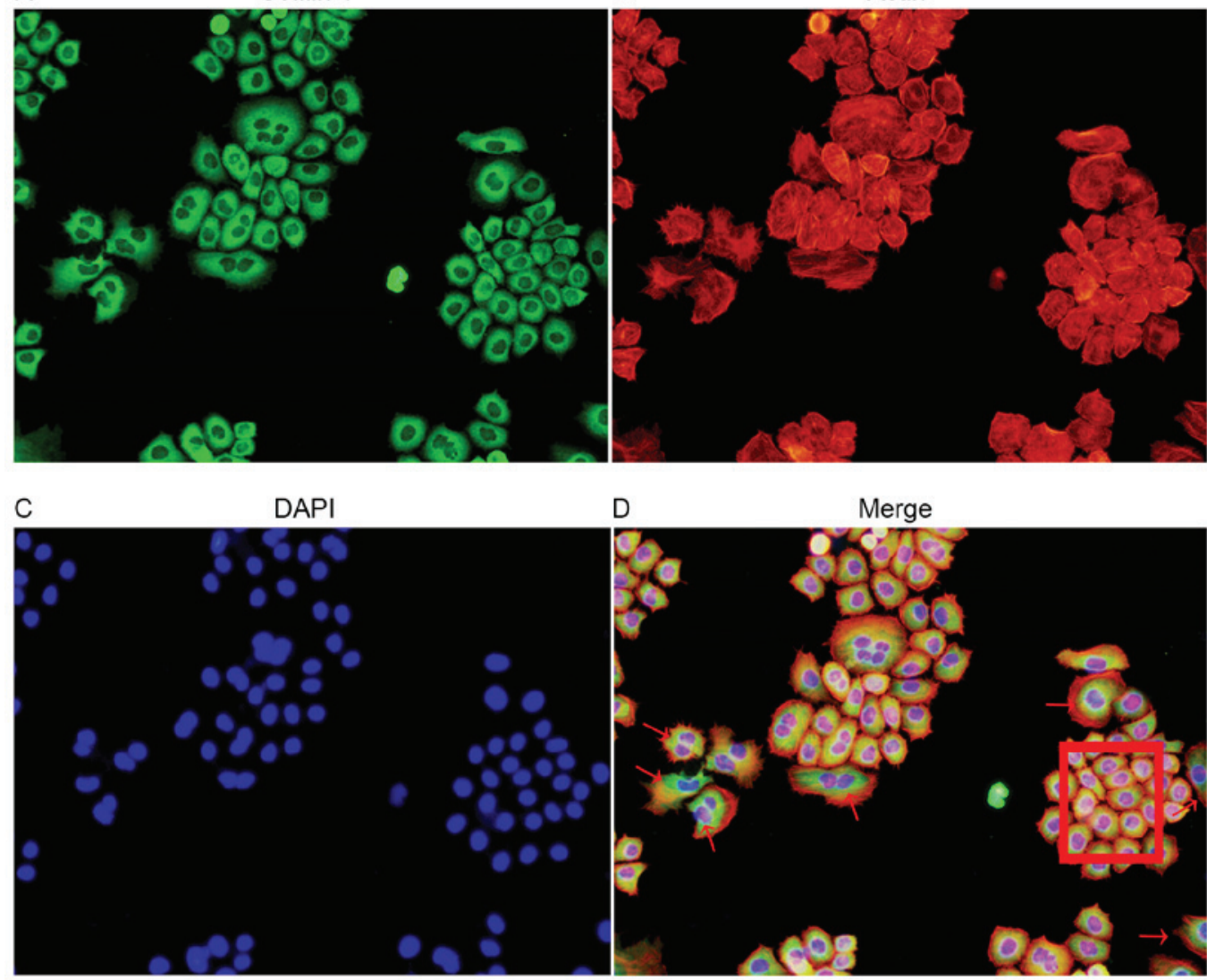

Figure 4. (A) Cellular immune fluorescence: Cofilin 1 expression in AGS cells undergoing EMT, induced by TGF- $\beta 1$. (B) Cytoskeleton staining: EMT was induced by TGF- $\beta 1$ in AGS cells, and then cells were stained with tetramethylrhodamine-conjugated Phalloidin. (C) Nuclear DAPI staining in AGS cells. (D) Merged images: By combining immunofluorescence and cytoskeleton staining methods, it was possible to observe that an increased level of Cofilin 1 expression accompanied the stretching out of lamellipodia and filopodia in EMT-induced AGS cells. The arrows indicate typical EMT cells and demonstrate that expression of Cofilin 1 in these cells was marked, as the cell cytoplasm was dark green. Cells in the red box exhibited Cofilin 1 expression in normal control cells (magnification, x200). EMT, epithelial-mesenchymal transition; TGF- $\beta 1$, transforming growth factor $\beta 1$.

Cytoskeleton staining detected by laser confocal microscopy. The negative control AGS cell group exhibited a distribution of microfilaments primarily on the cell membrane and cytoplasm, connected into a net. Cytoplasmic microtubules were stained uniformly with red fluorescence, and the cell borders around were clear with a small amount of microfilament formation (Fig. 6). Cytoskeleton staining in the model group demonstrated that the microfilament and skeleton structures were significantly altered compared with the negative control group. For example, cytoskeleton staining was darker, the microfilament grid structure was not clear and there was evidence of microfilament enrichment on the cell membrane. Cell morphology changed from an irregular quadrilateral shape into an oval appearance. The cells possessed increased invasion and metastasis abilities with long and rich microfilament tubules, a typical EMT cell form (Fig. 6). Treatment with $40 \mathrm{mg} / \mathrm{l} \mathrm{COE}$ for $24 \mathrm{~h}$ resulted in a restoration of the clear microfilament grid structure, and the number of microfilament bundle fibers on the cell membrane was reduced. The number of microfilament tubules around the cells was reduced, or disappeared in certain instances, and the cytoskeleton of the cells became partially dissolved or fractured. This indicated that COE may inhibit the changes in cytoskeleton and microfilament structure and distribution in AGS cells, as induced by TGF- $\beta 1$ (Fig. 6).

\section{Discussion}

Cell migration is a key step in malignant tumor invasion and metastasis events (16). Tumors spread through tumor cell invasion and migration into peripheral tissues. It is the primary reason why malignant tumor recurrence rates are high. EMT is an important biological process through which malignant tumor cells, derived from epithelium, achieve migration and invasion abilities (17). During this process, cell morphology changes; they become flatter and wider, and visible filopodia and lamellipodia form at the front of polarized cells. Under the action of the contractile forces of the cells, pseudopodia are stretched forward and pull the rear cell body forward (18). As an important regulatory factor of cell migration, Cofilin 1 adjusts the structure of filopodia and lamellipodia to promote cell migration (19). Clinical studies have revealed that Cofilin 1 is closely associated with pathological differentiation, tumor size, lymph node metastasis and clinical stages in gastric cancer, and serves an important function in the process of invasion and metastasis in gastric cancer $(8,20)$. As an important factor regulating tumor cell invasion and metastasis, Cofilin 1 regulation of EMT is primarily evident in the regulation of changes to the cell cytoskeleton, which reduces the dependence on the ECM for adhesive growth $(21,22)$. Cofilin 1 continuously regulates filamentous actin (F-actin) depolymerization and aggregation 
A
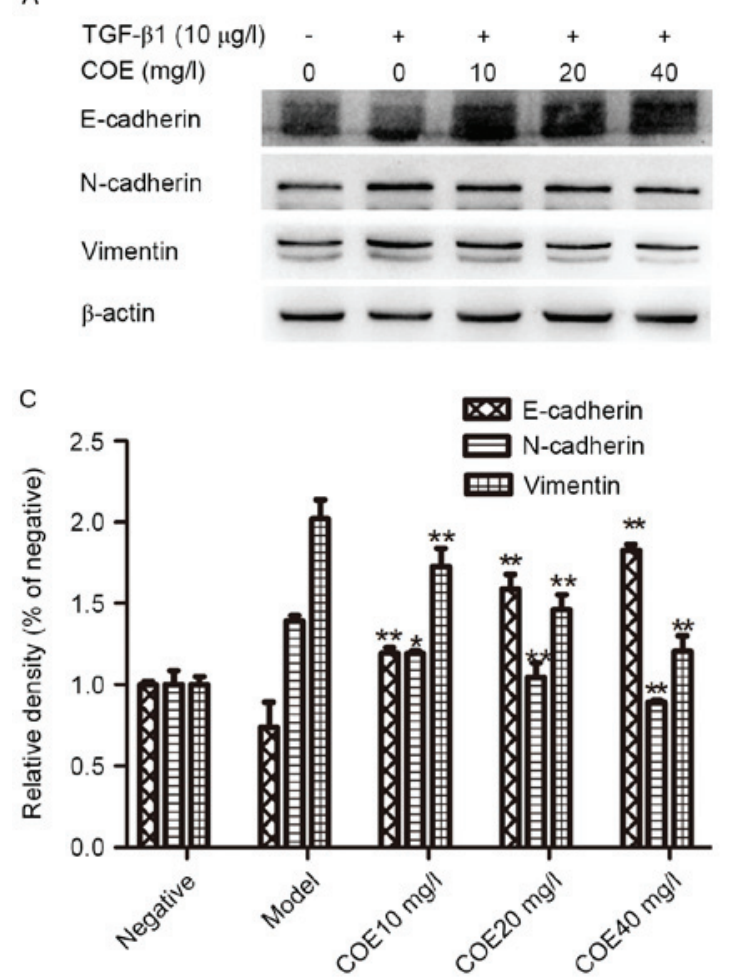

B

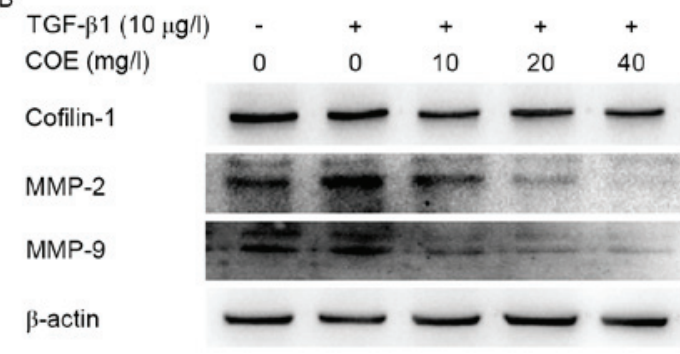

D

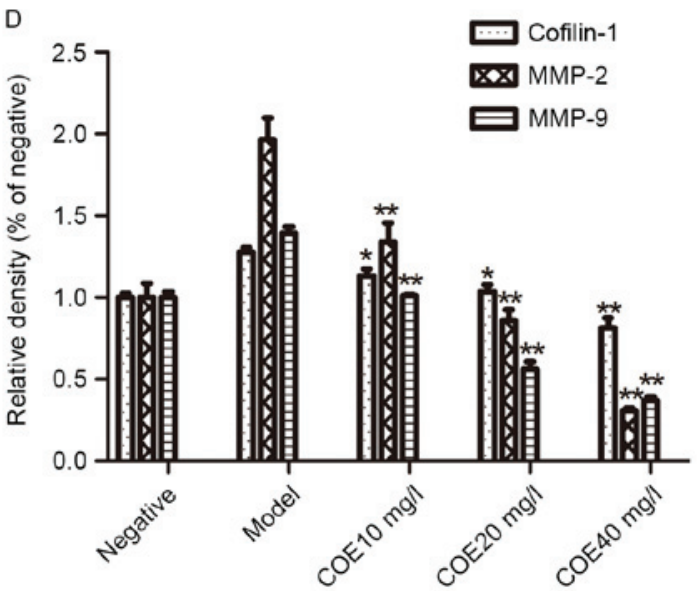

Figure 5. Changes in EMT biomarker expression levels following COE treatment for $24 \mathrm{~h}$, was (A) assessed by western blotting and (B) quantified. Changes in the expression levels of MMPs following treatment with $\mathrm{COE}$ for $24 \mathrm{~h}$ was (C) assessed by western blotting and (D) quantified. ${ }^{*} \mathrm{P}<0.05$ and ${ }^{* * *} \mathrm{P}<0.01 \mathrm{vs}$. control. EMT, epithelial-mesenchymal transition; COE, Celastrus orbiculatus extract; MMP, matrix metalloproteinase; E-cadherin, epithelial cadherin; N-cadherin, neural cadherin; TGF- $\beta 1$, transforming growth factor $\beta 1$.

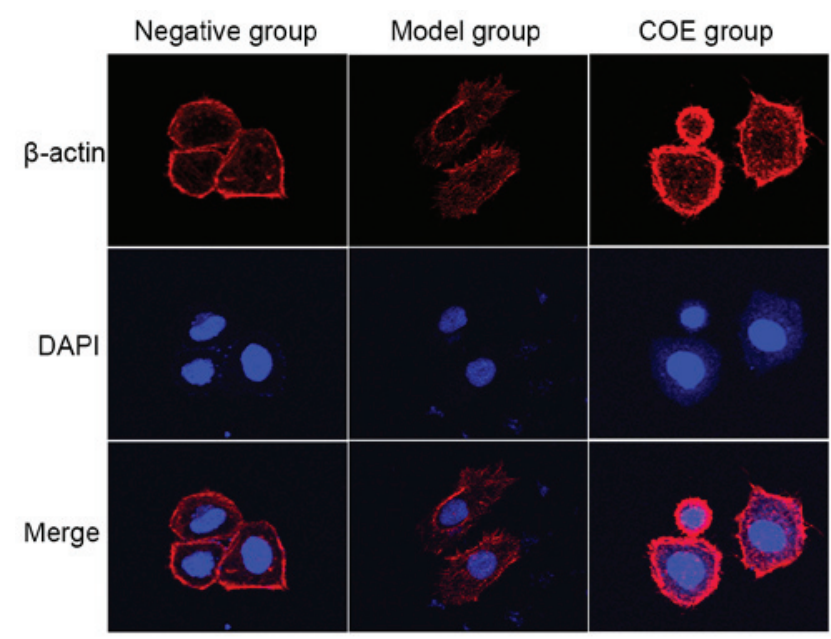

Figure 6. Changes in cell morphology, cytoskeleton and microfilament structure and distribution (magnification, $\mathrm{x} 400$ ). As demonstrated in the figure, COE may significantly inhibit the rearrangement of the cytoskeleton, which may reduce the morphological changes of the cells and inhibit the epithelial-mesenchymal transition process. COE, Celastrus orbiculatus extract.

in order to alter the cell cytoskeleton through nucleating the polymerization of F-actin fibres (23). Through reconstructing the front lamellipodium and lamellar structure of cells, this regulates cell 'steps' forward (24). The highly-localized activities of Cofilin 1 produce pseudopodia and determine the exact direction of cell movement, serving a function as the 'steering wheel' of cells (25).
Previous studies have identified that COE may inhibit tumor cell proliferation, invasion and metastasis (26-28). Its action may occur through inhibiting tumor cell transformation of epithelial-mesenchymal process to implement, but the specific mechanism is unclear. An experimental study revealed that COE may downregulate the expression level of Cofilin 1, thereby reducing the interaction of Cofilin 1 and F-actin (29). Cofilin 1 inhibits the depolymerization of F-actin by reducing the dissociation rate of actin monomers from the end of the fiber. As the depolymerization rate of F-actin is inhibited the changes to the cytoskeleton are impeded, which directly inhibits the EMT process of induced changes in morphology and cell invasion and metastasis abilities.

In the process of tumor invasion and metastasis, MMP family proteins are the most important proteases that degrade the ECM. In particular, MMP-2 and MMP-9 are closely associated with invasion and metastasis in gastric cancer (30). Following EMT in cells, the expression levels of MMPs rises (31). The present study revealed that in the control and intervention groups, the expression levels of Cofilin 1 and MMPs were consistent. Previous studies have demonstrated that the expression of Cofilin 1 reduces adhesion between the cells and ECM, and that Cofilin 1 activation may extend the actin chain, produce barbs at the ends, and determine the precise direction of the tumor cell movement. Silencing Cofilin 1 expression may increase adhesion between the cells and ECM $(32,33)$. This is in concordance with the results of the present study. Therefore, COE may reduce Cofilin 1-dependent changes to the cytoskeleton through directly inhibiting the expression of Cofilin 1, resulting in the inhibition 
of the EMT process of the cells. The suppression of the EMT process in tumor cells directly leads to decreased MMP-2 and MMP-9 protein expression levels (30). In the present study, detecting the expression levels of classic EMT biomarkers and MMPs indicated a direct inhibition of the EMT process.

In conclusion, $\mathrm{COE}$ may significantly downregulate Cofilin 1 protein expression levels in human gastric cancer AGS cells, thus effectively inhibiting alterations of the AGS cell cytoskeleton and suppressing EMT progress. Additional studies are required to investigate how to reduce the expression levels of Cofilin 1 protein.

\section{Acknowledgements}

The present study was financially supported by grants from the National Natural Science Foundation of China (grant nos. 81573656, 81450051 and 81403232) and the Natural Science Foundation of Jiangsu Province of China (grant no. BK20141280).

\section{References}

1. Chen W, Zheng R, Baade PD, Zhang S, Zeng H, Bray F, Jemal A, Yu XQ and He J: Cancer statistics in China, 2015. Ca Cancer J Clin 66: 115-132, 2015.

2. Ferlay J, Shin HR, Bray F, Forman D, Mathers C and Parkin DM: Estimates of worldwide burden of cancer in 2008: GLOBOCAN 2008. Int J Cancer 127: 2893-2917, 2010.

3. Flemban A and Qualtrough D: The potential role of hedgehog signaling in the luminal/basal phenotype of breast epithelia and in breast cancer invasion and metastasis. Cancers (Basel) 7: 1863-1884, 2015

4. Wang W, Mouneimne G, Sidani M, Wyckoff J, Chen X, Makris A, Goswami S, Bresnick AR and Condeelis JS: The activity status of cofilin is directly related to invasion, intravasation and metastasis of mammary tumors. J Cell Biol 173: 395-404, 2006.

5. Tahtamouni LH, Shaw AE, Hasan MH, Yasin SR and Bamburg JR: Non-overlapping activities of ADF and cofilin-1 during the migration of metastatic breast tumor cells. BMC Cell Biol 14: 45, 2013.

6. Han L, Stope MB, de Jesús ML, Oude Weernink PA, Urban M, Wieland T, Rosskopf D, Mizuno K, Jakobs KH and Schmidt M: Direct stimulation of receptor-controlled phospholipase D1 by phospho-cofilin. EMBO J 26: 4189-4202, 2007.

7. Wang WS, Zhong HJ, Xiao DW, Huang X, Liao LD, Xie ZF, $\mathrm{Xu}$ XE, Shen ZY, Xu LY and Li EM: The expression of CFL1 and N-WASP in esophageal squamous cell carcinoma and its correlation with clinicopathological features. Dis Esophagus 23: 512-521, 2010

8. Wu Y, Tang Y and Zhang Y: Clinicopathological significance of cofilin-1 in gastric cancer tissues. Cancer Res Prev Treat 39: 295-298, 2012

9. Cho HJ, Baek KE, Kim IK, Park SM, Choi YL, Nam IK, Park SH, Im MJ, Yoo JM, Ryu KJ, et al: Proteomics-based strategy to delineate the molecular mechanisms of RhoGDI2-induced metastasis and drug resistance in gastric cancer. J Proteome Res 11: 2355-2364, 2012.

10. Zhu Y, Liu Y, Qian Y, Dai X, Yang L, Chen J, Guo S and Hisamitsu T: Research on the efficacy of Celastrus orbiculatus in suppressing TGF- $\beta 1$-induced epithelial-mesenchymal transition by inhibiting HSP 27 and TNF- $\alpha$-induced NF- $\kappa B /$ Snail signaling pathway in human gastric adenocarcinoma. BMC Complement Altern Med 14: 433, 2014

11. Qian YY, Zhang H, Hou Y, Yuan L, Li GQ, Guo SY, Hisamits T and Liu YQ: Celastrus orbiculatus extract inhibits tumor angiogenesis by targeting vascular endothelial growth factor signaling pathway and shows potent antitumor activity in hepatocarcinomas in vitro and in vivo. Chin J Integr Med 18: 752-760, 2012.

12. Zhang H, Qian Y, Liu Y, Li G, Cui P, Zhu Y, Ma H, Ji X, Guo S and Tadashi H: Celastrus orbiculatus extract induces mitochondrial-mediated apoptosis in human hepatocellular carcinoma cells. J Tradit Chin Med 32: 621-626, 2012.
13. Xiao Ke, Chen Xiaoqing, Wang Qiang, et al: Research of chemical composition of celastrus orbiculatus Thunb. Chinese Herbal Med 38: 1455, 2007.

14. Li JJ, Yang J, Lu F, Qi YT, Liu YQ, Sun Y and Wang Q: Chemical constituents from the stems of Celastrus orbiculatus. Chin J Nat Med 10: 279-283, 2012.

15. Zan K, Chen X-Q, Wang Q and Cao L: Chemical constituents in stem of Celastrus orbiculatus. Chin Trad Herbal Drugs 38: $1455,2007$.

16. Croisé P, Estay-Ahumada C, Gasman S and Ory S: Rho GTPases, phosphoinositides, and actin: A tripartite framework for efficient vesicular trafficking. Small GTPases 5: e29469, 2014.

17. Felipe Lima J, Nofech-Mozes S, Bayani J and Bartlett JM: EMT in breast carcinoma - A review. J Clin Med 5: pii: E65, 2016.

18. Zhang S, Wu L, Liu Q, Chen $\mathrm{K}$ and Zhang X: Impact on growth and invasion of gastric cancer cell lines by silencing NEDD9. Onco Targets Ther 8: 223-231, 2015.

19. Delorme V, Machacek M, DerMardirossian C, Anderson KL, Wittmann T, Hanein D, Waterman-Storer C, Danuser G and Bokoch GM: Cofilin activity downstream of Pak1 regulates cell protrusion efficiency by organizing lamellipodium and lamella actin networks. Dev Cell 13: 646-662, 2007.

20. Wang W, Mouneimne G, Sidani M, Wyckoff J, Chen X, Makris A, Goswami S, Bresnick AR and Condeelis JS: The activity statusofcofilin is directly related to invasion, intravasation, and metastasis of mammary tumors. J Cell Biol 173: 395-404, 2006.

21. Gabrielsen M, Schuldt M, Munro J, Borucka D, Cameron J, Baugh M, Mleczak A, Lilla S, Morrice N and Olson MF: Cucurbitacin covalent bonding to cysteine thiols: The filamentous-actin severing protein Cofilin1 as an exemplary target. Cell Commun Signal 11: 58, 2013.

22. Oleinik NV, Helke KL, Kistner-Griffin E, Krupenko NI and Krupenko SA: Rho GTPases RhoA and Rac1 mediate effects of dietary folate on metastatic potential of A549 cancer cells through the control of cofilin phosphorylation. J Biol Chem 289: 26383-26394, 2014.

23. Galkin VE, Orlova A, VanLoock MS, Shvetsov A, Reisler E and Egelman EH: ADF/cofilin use an intrinsicmode of F-actin instability to disrupt actin filaments. J Cell Biol 163: 1057-1066, 2003.

24. Sidani M, Wessels D, Mouneimne G, Ghosh M, Goswami S, Sarmiento C, Wang W, Kuhl S, El-Sibai M, Backer JM, et al: Cofilin determines the migration behavior and turning frequency of metastatic cancer cells. J Cell Biol 179: 777-791, 2007.

25. Delorme V, Machacek M, DerMardirossian C, Anderson KL, Wittmann T, Hanein D, Waterman-Storer C, Danuser G and Bokoch GM: Cofilin activity downstream of Pak1 regulates cell protrusion efficiency by organizing lamellipodium and lamella actin networks. Dev Cell 13: 646-662, 2007.

26. Chang FR, Hayashi K, Chen IH, Liaw CC, Bastow KF, Nakanishi Y, Nozaki H, Cragg GM, Wu YC and Lee KH: Antitumor agents. 228. Five new agarofurans, reissantins A-E, and cytotoxic principles from Reissantia buchananii. J Nat Prod 66: 1416-1420, 2003.

27. Yuan L, Zhang H, Qian YY, Hou Y, Zhu YD, Ma H, Guo SY, Tadashi $\mathrm{H}$ and Liu YQ: Effects of serum containing Celastrus orbiculatus extracts on proliferation and VEGF-c expression in hepatoma cells of mice. Chin J Experimental Traditional Med Formulae 17: 157, 2011.

28. Yang Qingwei, Liu Li, Liu Weiwei, et al: Effects of Celastrus orbiculatus extract on suppressing invasion and metastasis of human hepatoma 7721 cells. Chin Herbal Med 40: 434, 2009.

29. Wang Haibo, Qian Yayun,Zhu Yaodong, et al: Effects of Celastrus orbiculatus extract on suppressing the epithelial-mesenchymal transition of human gastric adenocarcinoma cells by inhibiting cofilin 1 signaling pathway. Li Shi Zhen Medi Materia Medica Res 27: 303-307, 2016.

30. Hua H, Li M, Luo T, Yin Y and Jiang Y: Matrix metalloproteinases in tumorigenesis: An evolving paradigm. Cell Mol Life Sci 68: 3853-3868, 2011

31. Haibo W, Lide T, Feng J, Hao G, Xiaojun D, Tengyang N, Jun F, Yanbing D, Weiming X, Yayun Q and Yanqing L: Cofilin 1 induces the epithelial-mesenchymal transition of gastric cancer cells by promoting cytoskeletal rearrangement. Oncotarget, 2017 (Epub ahead of print)

32. Hitchcock-Degregori SE: Chemotaxis: Cofilin in the driver's seat. Curr Biol 16: R1030-R1032, 2006.

33. Estornes Y, Gay F, Gevrey JC, Navoizat S, Nejjari M, Scoazec JY, Chayvialle JA, Saurin JC and Abello J: Differential involvement of destrin and cofilin-1 in the control of invasive properties of Isreco1 human colon cancer cells. Int J Cancer 121: 2162-2171, 2007. 